\title{
Economics Of Summer Course Scheduling
}

Jess Boronico, (E-mail: jboronico@newhaven.edu), University of New Haven

Raja Nag, (E-mail: rnag@newhaven.edu), University of New Haven

\begin{abstract}
This paper addresses some of the relevant issues that University administrators face when determining a policy for academic coursework offered during the summer period, and the development of a mathematical model that may be used to guide management policy. It is suggested that the economic ramification of summer course policies may not be well understood, including understanding the potential long-term effect of discounting on summer per-credit charges. An empirical example is provided to demonstrate how administrators may utilize optimization and economic principles to address summer course pricing in an imperfect and ambiguous market.
\end{abstract}

\section{INTRODUCTION}

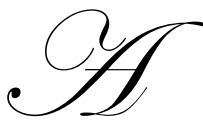

cademic administration faces significant challenges that are oftentimes ambiguous, in nature. As a loosely coupled system, there exist multiple constituencies to satisfy, each with vested interests that are often conflicting. For example, the complex simultaneous interrelationship between maximizing consumer welfare and increasing standards of service quality may conflict, as administration must consider the impact of decisions that attend to reputational capital but also cater towards fiscal responsibility. As a specific example, and one that is discussed here, administrators are interested in providing summer course offerings that are both of significant scale (credit hours offered) and scope (diversity of offerings) to meet and surpass consumer expectations but are also concerned with whether resulting decisions will lead to revenue generation that is sufficient to offset associated costs. Further complicating the matter is the ambiguous nature of the competitive market and the behavioral components that impact on consumer preference, both in the choice dimension of school as well as the scale dimension of enrollment (associated number of credit hours enrolled in).

Similar policy matters obtain during the traditional academic semesters, where departments and Colleges must consider the number and nature of classes to offer so as to ensure the timely degree completion of its student body, schedule classes in a way that minimizes potential conflict, offers the degree of diversity necessary to address concentration and major program requirements, and deploys faculty to adhere to the challenges and standards of accreditation bodies. These groups often impose criteria, driven by quality assurance standards, concerning the coverage of coursework, by discipline and degree path, with academically qualified faculty (AACSB, 2004; IACBE, 2007). Literature addressing timetabling, and the issues that impact on this, has appeared. For example, mathematical programming (Boronico, 2000) and heuristic approaches (Head and Shaban, 2007) have offered insight into the course scheduling challenges. Technology, by way of decision support models such as SchedulExpert at Cornell University, has also impacted on the ability of University administration to successfully address scheduling concerns (Hinkin and Thompson, 2002).

Concerning summer programming, credit hours are not typically included in full-time tuition or financial packages, and coursework is offered at a summer per-credit rate often differentiated from the charge that is incurred during the fall and/or spring. Discounting is often used to encourage enrollment. The literature supports the importance of summer programming as an alternative scheduling format to serve the multiplicity of student requirements (LaFountain, 1995), address or ensure timely degree completion, strengthen summer abroad programming and experiential learning during an off-peak enrollment season, and increase efficient classroom utilization (Archer and Armacost; 2006). However, the market for summer programming, while bearing the earmarks of other service providers, does not appear to be as well understood. For example, summer pricing options are often left in the hands of an administration or Board of Governors who is not informed of important economic ramifications, modeling results, or the translation of results available elsewhere to academia, as they exist in other industries. For example, for those results that have been generated exploring the impact of student responses to 
tuition increases (Chressanthis, 1986; Funk, 1972), "institutional enrollment planning models generally have not had the opportunity to use recent research on student price response" (St. John, 1992). Moreover, although findings do support the intuitive result that tuition increases typically reduce college enrollments (Remus and Isa; 1983), results further suggest that the impact is sometimes small (Savoca, 1990), and inelasticity of demand has resulted in recommendations for maintaining summer rates, as opposed to discounting, although discounting is a prevalent practice (Summer Session Advisory Committee, 1998). Finally, the literature has not considered, at depth, many of the behavioral factors that typically impact on decision making (Bazerman, 2006) in the context of consumer summer enrollment decisions.

In order to more fully understand the impact of price changes on summer enrollment and the subsequent impact on the financial viability of such programmatic offerings, a model is suggested here to assist decision makers in addressing these concerns and forming satisficing, or perhaps optimal pricing strategies for summer program offerings. Implications for future research that would benefit educational administration are also suggested. The modeling further considers the delicate issue of including sufficient information so as to warrant its use, but simultaneously recognizes that unnecessary complication or increased ambiguity in modeling may result in the enduser not assuming ownership of the results, wherein the model potentially loses its applicability in practice.

\section{THE MODEL}

\section{The Research Question And Data Collection}

The basic research question involves ascertaining an optimal price level, and considering the number and diversity of courses offered during summer that will meet the objectives of a University. These University objectives typically involve benchmarks for financial performance, but also include somewhat ambiguous or subjective targets related to consumer satisfaction. The specific model that is presented, below, considers the decision for the pricing of summer credit hours, including the consideration of associated direct costs of instruction, and the long-term financial implication of students graduating early due to significant credit hours being earned through summer enrollment.

The study, based on information gathered from the University of New Haven (UNH), will be considered as preliminary decision support for guiding management policy and a basis for ongoing studies, designed to assist the administration in pricing and scheduling summer programming alternatives.

The standard tuition rate for UNH full-time undergraduate students is $\$ 12,000$ per semester, covering up to seventeen credit hours, or $\$ 705$ per credit hour (assuming a full seventeen credit-hour load). In order to encourage summer enrollment the University currently discounts the summer per-credit hour rate to $\$ 400$. The University wishes to continue offering summer courses for the reasons cited earlier, and is concerned that increasing the summer rate or enforcing a full-charge pricing policy may damage reputational capital, and also decrease enrollment due to the competition in the local area. The University wishes to maintain sufficient diversity (scope) and number (scale) of course offerings to meet student expectations, which are not well understood. Most local competitors also engage in summer discounting, with local community colleges providing the least-cost alternatives to UNH students. To date there has been little, if any, effort devoted to collaboration between competitive local institutions to understand the nature of the market and utilize this information in resolving the common institutional pricing challenges.

The initial phase of the study involved gauging student demand for summer courses. This was approached by way of surveying UNH undergraduate full-time students, with 132 students responding. General findings of the study indicate that:

1. 88 percent of students have a strong interest in attending summer classes;

2. 69 percent of students would consider attending UNH for summer courses. This prevailing rate exceeded the percentage that demonstrated an interest in attending a community college (60 percent) or four-year public institutions (47 percent), despite the cost differential/savings offered at the local community and public institutions. This was interpreted as brand loyalty to the home school (UNH). Similar findings have been noted elsewhere (Krishnamurthi and Raj, 1991); 
3. The most often cited factor for attending summer school is to complete requirements for graduation quickly ( 86 percent). Other factors include uniqueness of course offerings in the summer (52 percent), and avoiding overloads in the fall and spring (55 percent). Very few respondents are concerned with retaking a course or improving their grade (14 percent);

4. Students are primarily interested in summer courses in the general education core curriculum (71 percent), followed by upper division major requirements ( 57 percent). 82 percent of respondents are interested in online coursework;

5. Consideration of financial aid is a factor for 90 percent of respondents in choosing whether to attend summer school. This would partially explain the desire to attend summer school at discounted rates, since regular session tuition is subsidized through a diverse set of financial assistance packages. While not considered here, the implication to academic financial aid packages and the enrollment strategies to attend to this matter form implications for future research;

6. Only 53 percent of students indicate that they would be willing to pay the regular full-charge semester rate to take summer courses, although this survey percentage increases as price decreases, to 81 percent if tuition is discounted by 50 percent for summer credit hours. Only 9 percent of students are willing to consider summer courses if the summer per-credit charge exceeded the full-semester charge by five percent;

7. Current summer enrollment credit hours have been relatively stable during the most recent three-year window, averaging 2100 credit hours per summer. The UNH inflation-adjusted summer per-credit charge has remained stable during this period.

\section{The Mathematical Analysis}

Student responses concerning their willingness to take summer credit hours at various price levels were utilized to create a derived demand function. Utilizing a least-squares objective function and employing an exponential variable-elasticity demand format;

$$
D=\alpha-\beta \delta^{\gamma P}
$$

the following optimal least-square parameter values obtain:

$$
\alpha=88.56, \beta=.000011, \delta=1.669, \gamma=.04
$$

The resulting demand curve is shown in Figure 1:

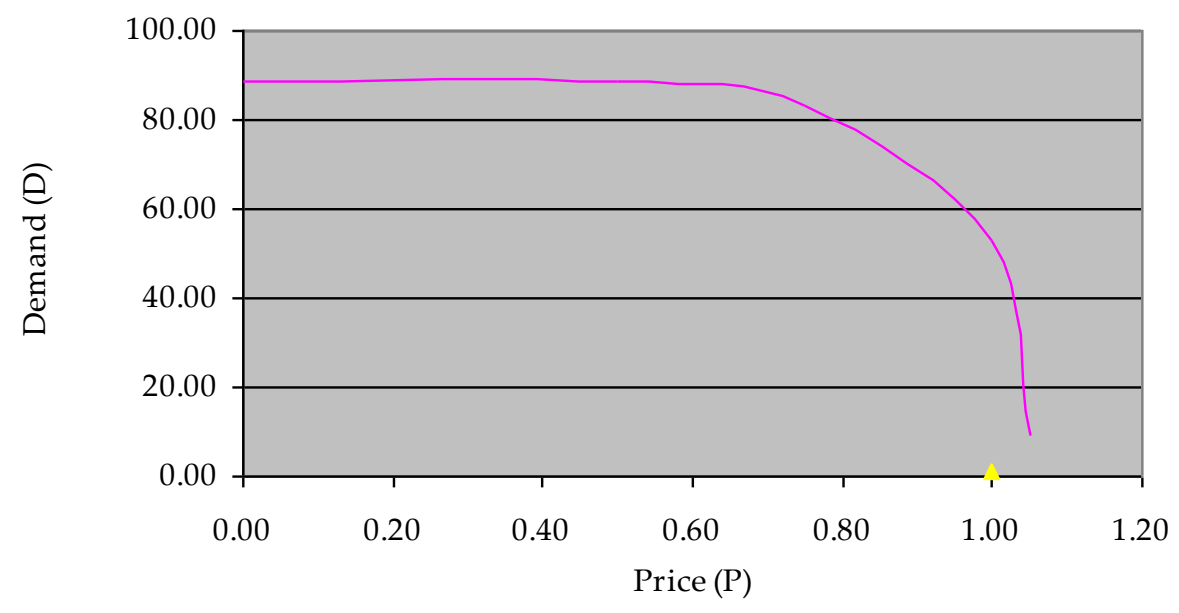

Figure 1: Projected Summer Enrollment Demand Curve 
The price units $(P)$ are expressed as a ratio between suggested summer per-credit charges and the current per-credit charge for tuition during the Fall/Spring semester. Demand units $(D)$ represent the survey elicited percentage of students that are willing to enroll in a summer course at each given price level. Table one provides a few arc elasticities for this demand across the price spectrum:

Table 1: Selected arc-elasticities

\begin{tabular}{|c|c|}
\hline Range: summer/full tuition per-credit hour ratio & Arc elasticity \\
\hline$[.25, .50]$ & -0.001 \\
\hline$[.50, .75]$ & -0.019 \\
\hline$[.75,1.0]$ & -1.182 \\
\hline$[1.0,1.05]$ & -16.488 \\
\hline
\end{tabular}

Results are consistent with those found elsewhere. Specifically, greater tuition results in higher levels of own-price demand elasticity. Changes in elasticity may be related to additional factors, cited elsewhere, such as substitution effects (Weiler, 1984), and are left as implications for additional research, as are cross-elasticities and the direct consideration of competitor pricing. Results also demonstrate Weiler's (1984) finding that elasticity increases dramatically above a "threshold" price. Figure 1 suggests that this threshold occurs when the summer tuition charge exceeds approximately 60 percent of the full-semester per-credit charge.

The current summer per-credit charge of $\$ 400$ represents $P=400 / 705=.567$. Utilizing equation (1), the resulting demand is $D=.885$, which is equated to the three-year summer enrollment average for UNH of 2100. Utilizing point elasticity $(\square)$ and setting $\varepsilon=-1$ for the derived demand curve results in revenue maximization, which occurs at a summer price level of $\$ 625$ per-credit. The resulting demand is 1951 student credithour enrollments with associated revenues of $\$ 1,219,160$. The overall revenue curve is shown below, in Figure 2:

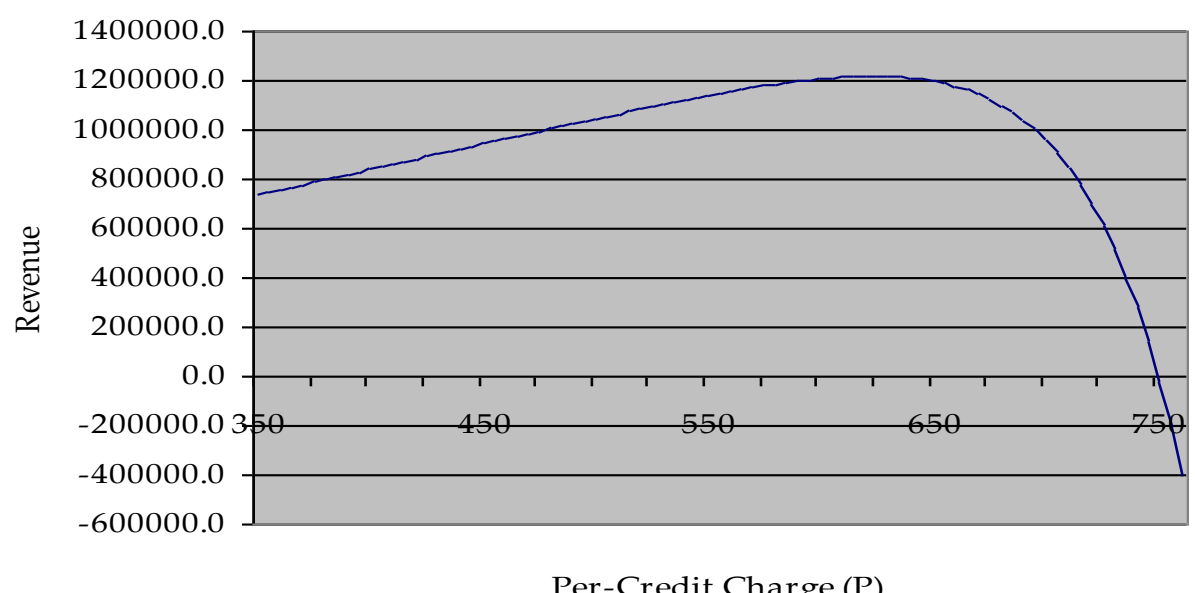

Figure 2: Projected Revenue Curve

Utilizing a target class size of ten students, aligned with UNH's reputation of desire to adhere to strong student support and small class sizes (UNH's average class size for the Fall and Spring undergraduate program is thirteen), and assuming that students registering in the summer will choose to distribute themselves somewhat uniformly across the scope of classes offered, it is straightforward to project the number of classes required to meet credit-hour demand (demand divided by average class size, or 10). It is further assumed here that all summer courses are staffed at the typical summer undergraduate adjunct compensation rate and that the analysis is first 
limited to the integration of only the direct cost of instruction (including benefits). Using $\$ 2500$ per three-credit course as the base compensation rate for summer instruction, Figure 4 demonstrates the impact of the integration of the direct cost of instruction on price, which is determined so as to maximize expected profit:

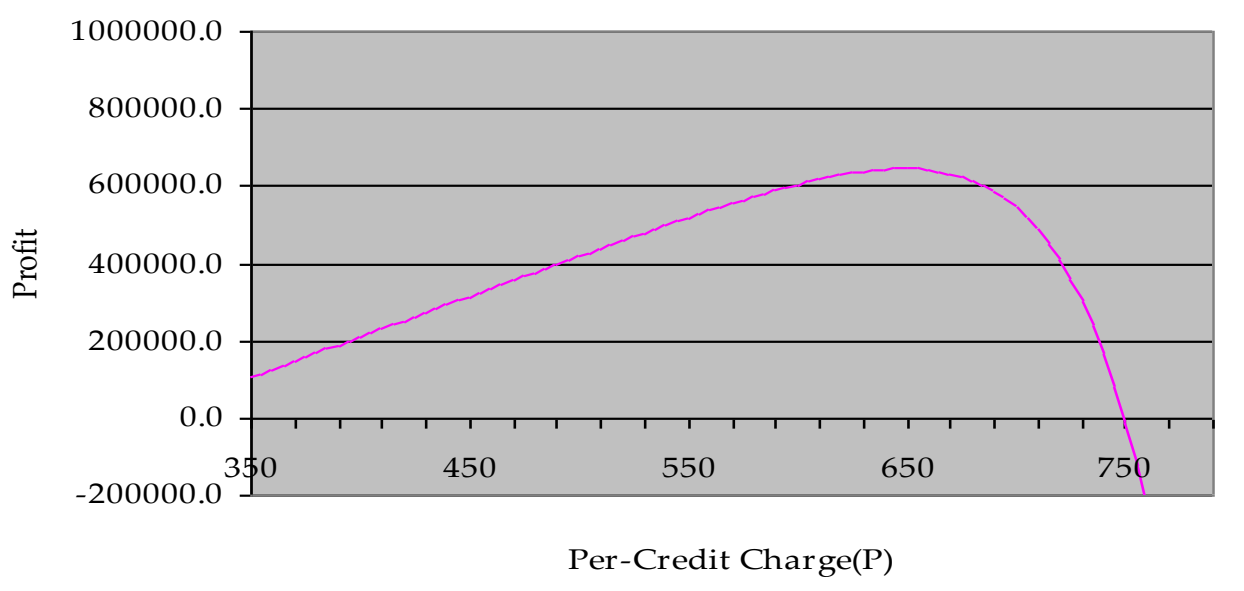

Figure 3: Profit Curve

The multivariable simultaneous consideration of both price and class size as decision variables forms an interesting extension of this model but is left as a future implication for research. Results of the current analysis suggest a profit-maximizing price of $\$ 645$ per summer credit hour, an increase from the revenue maximizing price of $\$ 625$. Resulting maximum profits are $\$ 645,501$ with corresponding student demand for 1871 credit hours, a decrease from the 1951 credit hour demand at the revenue maximizing price. It is noted that the revenue maximizing price results in profits of $\$ 633,963$ and that the projected profit at the current charge of $\$ 400$ is $\$ 210,017$ with projected credit-hour demand of 2100 credit hours. As previously noted, the number of classes required obtains directly by dividing the credit-hour enrollment by the desired class size (10). These results are summarized below, in Table 2:

Table 2: Output Summary

\begin{tabular}{|c|c|c|c|c|}
\hline Scenario & Price & Revenue & $\begin{array}{c}\text { Projected Credit- } \\
\text { Hour Demand }\end{array}$ & Profit \\
\hline Current & 400 & 840,067 & 2100 & 210,017 \\
\hline Revenue Max & 625 & $1,219,160$ & 1951 & 633,963 \\
\hline Profit Max & 645 & $1,206,806$ & 1871 & 645,501 \\
\hline
\end{tabular}

Lastly, the model is extended by considering an approximated cost of students graduating early due to completion of significant numbers of summer credit hours. It is noted that 111 of the 207 AY06 undergraduate program completers had successfully completed six or more summer credit hours during their college career. Given the 120 credit-hour UNH program completion requirement, students completing fifteen summer credit hours would graduate one semester earlier than they would without any summer credit hours. Students that have completed between six and twelve such credit hours may complete their degree program by enrolling at the part-time rate of $\$ 800$ per credit hour and avoiding the full-time per semester charge of $\$ 12,000$. We assume that these students do not enroll in limited fall/spring evening courses that are offered at a fifty (50) percent discount. The lost revenue accrued per student, based on the number of total credit hours completed during summer sessions, is summarized below, in Table 3: 
Table 3: Early Completer Costs

\begin{tabular}{|c|c|c|c|c|}
\hline $\begin{array}{c}\text { Summer credit hours } \\
\text { completed }\end{array}$ & $\begin{array}{c}\text { Credit hours } \\
\text { required in the final } \\
\text { semester }\end{array}$ & Number of Students & $\begin{array}{c}\text { Total credit-hour } \\
\text { charge } \\
\mathbf{\$ 8 0 0 / c r e d i t ~ h o u r ~})\end{array}$ & $\begin{array}{c}\text { Net loss for the } \\
\text { University }\end{array}$ \\
\hline $6-8$ & 9 & 38 & 7200 & $12,000-7200=4800$ \\
\hline $9-11$ & 6 & 15 & 4800 & $12,000-4800=7200$ \\
\hline $12-14$ & 3 & 11 & 2400 & $12,000-2400=9600$ \\
\hline 15 or more & 0 & 47 & 0 & 12,000 \\
\hline
\end{tabular}

*(Based on graduating class of 2006)

We note the following:

1. The average loss per student, based on the Table 3 data, weighted by the number of students in each category, is $\$ 8,649$;

2. At the current summer charge of $\$ 400$ per summer credit-hour, 111 of 207 AY06 graduates, or 54 percent, complete their degree one semester early (we exclude those few students who have completed sufficient credit-hours during summer to fulfill degree requirements one full year early, as they form less a very small subset of these students), and are able to complete degree requirements at part-time enrollment rates (thus avoiding the full-semester tuition charge);

3. Only eight of the 207 graduates did not complete any summer credit hours;

4. It is assumed that the "early completer" cost will only enter the analysis for that percentage of students on whom the pricing decision impacts. That is, we assume that $\varepsilon$ percentage of early completers would complete program requirements early regardless of the summer pricing policy at UNH. For these students, the cost of early completion is considered a sunk cost. Administration has indicated a suggested value of $50 \%$ for $\square$, hence the early completer cost will enter the analysis for the remaining $1-\varepsilon=50$ percent of the early completers. For the base of 111 such students this represents approximately 55 students. The resulting early completer cost at the current summer per-credit charge of $\$ 400$ is therefore estimated at: 55 students $\cdot \$ 8649$ cost $/$ student $=\$ 475,695$.

For other feasible summer per-credit charges, the number of early completers will be assumed proportional to the ratio of the projected credit hour enrollment at the proposed summer per-credit-hour price and that at the current charge of $\$ 400$. For example, at the current summer credit-hour rate of $\$ 400$, projected enrollment is 2024 credit hours. If the summer per-credit-hour price were increased to the revenue maximizing price, $\$ 625$, the resulting projected enrollment would decrease to 1951 credit hours, and the administration approximates that the resulting early-completer cost would decrease to $(1951 / 2100) \cdot 55 \cdot \$ 8649=\$ 441,943$. Consideration of how early completion varies as a function of price, and other factors, is left as an implication for future research. Inclusion of this early-completer cost results in the profit curve below, in Figure 4: 


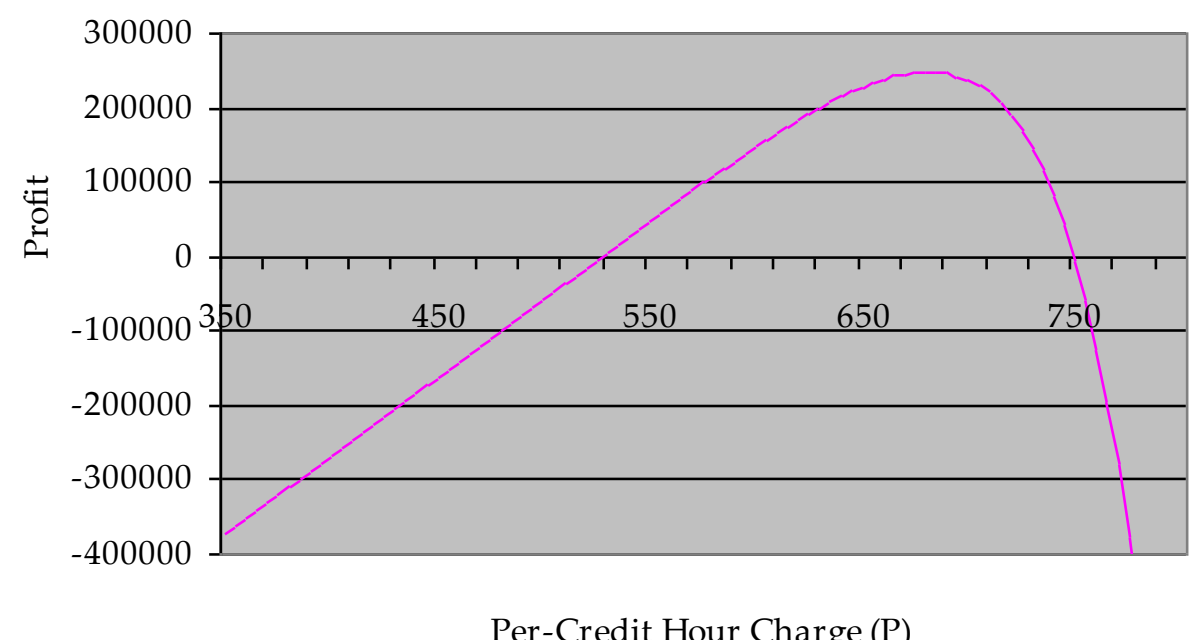

Figure 4: Profit Curve including Early-Completer Cost

Note that significant net losses accrue for a wide range of price levels, including the current price of $\$ 400$ per credit hour. The intuitive optimal result obtains, namely, optimal price will rise when introducing the earlycompleter cost. Specifically, the profit-maximizing price increases to $\$ 680$ with a resulting profit of $\$ 248,277$. Credit-hour projected demand decreases to 1618. The resulting price represents a three (3) percent discount, from full-tuition credit charges, for summer credit hours.

Overall results for the analysis are summarized, below, in Table 4.

Table 4: Summary Data (Optimal figures in bold)

\begin{tabular}{|c|c|c|c|c|c|}
\hline Scenario & $\begin{array}{c}\text { Price } \\
\mathbf{( \$ )}\end{array}$ & Revenue (\$) & $\begin{array}{c}\text { Projected } \\
\text { Demand (CH) }\end{array}$ & $\begin{array}{c}\text { Profit (\$) w/o } \\
\text { early } \\
\text { completers }\end{array}$ & $\begin{array}{c}\text { Profit (\$) w/ } \\
\text { early } \\
\text { completers }\end{array}$ \\
\hline Current & 400 & 840,067 & 2100 & 210,017 & $-265,678$ \\
\hline Revenue Max w/o early completers & 625 & $\mathbf{1 , 2 1 9 , 1 6 0}$ & 1951 & 633,963 & 192,133 \\
\hline Profit Max w/o early completers & 645 & $1,206,806$ & 1871 & $\mathbf{6 4 5 , 5 0 1}$ & 221,709 \\
\hline Profit Max w/ early completers & 680 & $1,099,883$ & 1618 & 614,641 & $\mathbf{2 4 8 , 2 7 7}$ \\
\hline
\end{tabular}

\section{DISCUSSION AND IMPLICATIONS FOR FUTURE RESEARCH}

The objective of this analysis was to provide our University administration with a fundamental, yet meaningful economic model to guide decision making in the area of summer per-credit pricing policy. Results are based on student survey information coupled with a consideration of revenue and profit-maximizing objectives, and include the impact of direct instructional costs as well as early completer costs. General results suggest that the current summer per-credit charge is sub-optimal, in that it fails to achieve either revenue or profit maximization. Specifically, administration should consider increasing the summer per-credit charge from $\$ 400$ to a value in the neighborhood of [ $\$ 625, \$ 680]$, the exact value ascertained by preference related to (a) the extent to which revenue and profit maximization are emphasized, (b) the degree of consideration given to direct instructional costs and early completer cost, and (c) the perceived risk that the administration wishes to take in changing summer rates in the light of ambiguity presented in market conditions and reliability of data sets available. 
The results demonstrate that even at the current summer per-charge of $\$ 400$, revenues are sufficient to cover direct instructional costs, although this is not true if the early-completer cost is included. While the appropriate impact that pricing has on this early-completer cost forms an open question, it is suggested here that some credibility be given to these early-completer results and that the summer per-credit charge be increased incrementally towards the suggested optimal solution. There are significant additional components of the analysis that can be expanded on, as well, in order to add significance to the results. Of course, care must be taken by way of considering the "value added" of additional information against the increased ambiguity for those modeling considerations that are illdefined, as well as any resulting uncertainty in the validity of the results obtained. Finally, survey results indicate that summer programming scope focus on general education core-curricular offerings coupled with unique upperdivision major-specific courses, including online or hybrid delivery mechanisms. The suggested number of sections offered over the aforementioned recommended price range varies between $(195,162)$ as the price increases.

Implications for future research include strengthening the integration of competition directly into the model by way of an economic analysis that introduces competitive prices, cross-elasticities and market demand, and juxtaposing competitors' enrollments and price changes in the context of the academic summer market setting. Although the results between previous studies have been somewhat incompatible (Leslie \& Brinkman, 1987), the extension of the model to include (in addition to price) student characteristics (e.g. family income) and sociological variables of the student pool, student financial-aid structure, and the University competitors' demographics may be desirable; expanding the analysis to include part-time students, adult evening students, and graduate students, as well as their preferences would also be considerations for expanding the model. The student survey instrument and its method of delivery could also be further developed to include questions that are framed in a way that elicits responses that will better attend to the deriving the demand curve. For example, previous studies have included the use of poster sessions to provide more complete information to participants.

A better understanding of how financial aid packages might be reconfigured to enhance the benefit of summer programming to both the institution and the student, and the impact of framing effects related to existing findings that "students ordinarily show greater sensitivity to tuition changes than per-student aid changes" (Leslie and Fife, 1974) also form implications for model extension. Although tuition is highly visible, financial aid can be more effective, if considered carefully, due to its restrictive and targeted nature (Jackson, 1978). In addition, the model can include not only the "choice" question (i.e. what school will be attended during summer periods), but the "quantity" question as well, which impacts on the number of credit-hours taken. It is shown elsewhere that "loyalists" are less price sensitive than "non-loyalists" in the choice decision, but more price sensitive in the quantity decision (Krishnamurthi and Raj, 1991). The level of brand loyalty to UNH has not been studied. Further exploration into the early-completer groups and the factors that influence their summer enrollment choice decision might also be warranted.

Finally, a broadening of the model to include either consumer welfare or a utility approach may be considered in this setting (Jackson and Weatherby, 1975), and the model can be extended to include indirect costs (i.e. Activity-Based cost accounting), as well as quality dimensions. The linguistic nature of many model parameters and variables also suggests that fuzzy logic or a fuzzy control system may be employed.

\section{CONCLUDING COMMENTS}

The question of how academic institutions should price their summer program offerings, the diversity and scale of classes offered, and the delivery systems utilized are important policy issues that are faced by virtually all Universities. The conflicting nature of objectives that address fiscal responsibility, balancing cost recovery with reputational capital, student expectations, and timely degree completion initiatives offers a fertile ground for future research that is practical and essential. The analysis here demonstrates how an administration can incorporate economic foundations and survey data to generate results that can guide management policy under varying and alternative conditions. The utilization and extension of such results can hopefully result in increased efficiency in resource utilization, with subsequent policy implications resulting in greater consumer satisfaction. 


\section{REFERENCES}

1. Archer, S. and Armacost, R. (2006) Enrollment Planning Workgroup Report July 2006, University of Central Florida - University Analysis and Planning Support Unit.

2. Bazerman, M (2006) Judgment in Managerial Decision Making, $6^{\text {th }}$ edition, New York: John Wiley \& Sons, Inc.

3. Chressanthis, G. A. (1986) The impacts of tuition rate changes on college undergraduate headcounts and credit hours over time - A case study, Economics of Education Review, 5, 205-17.

4. Funk, H. J. (1972) Price elasticity of demand for education at a Private University, Journal of Educational Research, 66 (November), 130-34.

5. Head, C. and Shaban, S. (2007) A heuristic approach to simultaneous course/student timetabling, Computers \& Operations Research, 34(4), 919.

6. Hinkin, T. R. and Thompson, G. M. (2002) SchedulExpert: Scheduling courses in the Cornell University School of Hotel Administration, Interfaces, 32 (6), 45-58.

7. Jackson, G. A. and Weatherby, G. B. (1975) Individual Demand for Higher Education: A review and analysis of recent empirical studies, Journal of Higher Education, 46(6), 623-52.

8. Jackson, G. A., (1978) Financial aid and student enrollment, Journal of Higher Education, 49 (September/October), 548-74.

9. Krishnamurthi, L. and Raj, S. (1991) An empirical analysis of the relationship between brand loyalty and consumer price elasticity, Marketing Science, 10 (Spring), 172-83.

10. LaFountain, R. M. (1995) The effect of scheduling on long-term retention, Innovative Higher Education, 20 (Falk), 19.

11. Leslie, L. L. and Fife, J. D. (1974) The College student grant study: The enrollment and attendance impact of student grant and scholarship programs, Journal of Higher Education, 45 (November/December), 65171.

12. Remus, W. and Isa, D. (1983) Predicting actual University enrollments, College Student Journal, 17 (Summer), 137-40.

13. Savoca, E. (1990) Another look at the demand for higher education: Measuring the price sensitivity of the decision to apply to College, Economics of Education Review, 9, 123-34.

14. St. John, E. P. (1992) Changes in pricing behavior during the 1980s: An analysis of selected case studies, Journal of Higher Education, 63, 165-87.

15. Summer Session Advisory Committee (1998) Recommendations for the future of the summer session at the University of Wyoming.

16. Weiler, W. (1984) Using enrollment demand models in institutional pricing decisions, Issues in Pricing Undergraduate Education, New Directions for Institutional Research (42), L. H. Litten: Editor, SanFrancisco: Jossey Bass. 
NOTES 